\title{
Dielectric properties and structural dynamics of melt compounded hot-pressed poly(ethylene oxide)-organophilic montmorillonite clay nanocomposite films
}

\author{
R J SENGWA* and SHOBHNA CHOUDHARY \\ Department of Physics, J N V University, Jodhpur 342 005, India
}

MS received 9 January 2010; revised 16 June 2011

\begin{abstract}
The dielectric properties of melt compounded hot-pressed nanocomposite films consisting of a poly(ethylene oxide) (PEO) and organophilic montmorillonite (OMMT) clay surface modified with trimethyl stearyl ammonium as filler with increasing amount up to $20 \mathrm{wt} \%$ OMMT were investigated in a frequency range of $20 \mathrm{~Hz}-$ $1 \mathrm{MHz}$ at $30{ }^{\circ} \mathrm{C}$. The predominance of OMMT exfoliated structures in PEO-OMMT nanocomposites were recognized by a decrease of the real part of complex dielectric function. OMMT concentration dependent dielectric and electric modulus relaxation times have revealed that the interactions compatibility between PEO molecules and dispersed OMMT nano-platelets in PEO matrix governs the PEO segmental dynamics. A.C. conductivity of these nanocomposites increases by two orders of magnitude in the experimental frequency range.
\end{abstract}

Keywords. PEO-OMMT nanocomposites; dielectric relaxation; electrical conductivity; impedance spectroscopy.

\section{Introduction}

Synthesization and structural characterization of polymerclay nanocomposite (PCN) films and colloids have been an intense topic of industrial and academic research (Tunney and Detellier 1996; Ogata et al 1997; Liao et al 2001; Shen et al 2002, 2003; Chaiko 2003; Strawhecker and Manias 2003; Chen and Evans 2004; Lin-Gibson et al 2004; Nelson and Cosgrove 2004; Homminga et al 2005; Reinholdt et al 2005; Elmahdy et al 2006; Hikosaka et al 2006; de Bruyn et al 2008; Liu et al 2008; Miwa et al 2008; Sengwa et al 2008, 2009a-c, 2010a-c; Sengwa and Choudhary 2010, 2011). These investigations on organic-inorganic nanocomposites established that the interactions between polymer (organic phase) and intercalated/exfoliated nano-platelets of clay (inorganic phase) at a molecular level enhances the mechanical, thermal, permeation, optical, chemical and electrical properties as compared to the virgin polymer matrix. The hydrophilic nature of linear chain dipolar poly(ethylene oxide) (PEO) and also of montmorillonite (MMT) clay plays an important role in the development of desired physical and electrical properties of the nanocomposite material by adjusting MMT concentration in the polymer matrix. Besides MMT concentration the pre-treatment of mixing and preparation route of the nanocomposites also govern their physical and electrical properties (Shen et al 2003; Hikosaka et al 2006).

The nanocomposites comprising of PEO with MMT as filler are extensively synthesized by solution intercalation

\footnotetext{
*Author for correspondence (rjsengwa@ rediffmail.com)
}

technique and sometimes also by melt compounding process (Tunney and Detellier 1996; Ogata et al 1997; Liao et al 2001; Shen et al 2002, 2003; Chaiko 2003; Strawhecker and Manias 2003; Chen and Evans 2004; Lin-Gibson et al 2004; Nelson and Cosgrove 2004; Homminga et al 2005; Reinholdt et al 2005; Elmahdy et al 2006; Hikosaka et al 2006; de Bruyn et al 2008; Liu et al 2008; Miwa et al 2008; Sengwa et al 2009a; Sengwa and Choudhary 2011). The characterization of these PCNs by various spectroscopic and morphological measurements established that PEO molecules have excellent intercalation in $\mathrm{Na}^{+}-\mathrm{MMT}$ and $\mathrm{NH}_{4}^{+}-$ MMT galleries due to their hydrophilic behaviour, good adhesion and favourable interactions compatibility between the PEO and MMT nano-platelets. Further, the amount of intercalated PEO in MMT galleries and adsorbed PEO on MMT exfoliated surfaces anomalously vary with the increase of MMT concentration (Tunney and Detellier 1996; Ogata et al 1997; Liao et al 2001; Shen et al 2002, 2003; Chaiko 2003; Strawhecker and Manias 2003; Chen and Evans 2004; Lin-Gibson et al 2004; Nelson and Cosgrove 2004; Homminga et al 2005; Reinholdt et al 2005; Elmahdy et al 2006; Hikosaka et al 2006; de Bruyn et al 2008; Liu et al 2008; Miwa et al 2008; Sengwa et al 2010a; Sengwa and Choudhary 2011). As compared to $\mathrm{Na}^{+}-\mathrm{MMT}$, the ion exchange MMT (replacing the original small cations by more bulky one) have large compatibility of polymers to easily intercalate because the bulky ion surface modification increases the MMT interlayer spacing (Passaglia et al 2008).

Several investigations on solid and colloidal PCNs confirmed the potential use of dielectric spectroscopy for the structural characterization of dispersed MMT in polymer matrix and the hindrance to polymer chain dynamics 
(Kanapitsas et al 2002; Böhning et al 2005; Bur et al 2005; Noda et al 2005; Elmahdy et al 2006; Mijović et al 2006; Pluta et al 2007; Psarras et al 2007; Rao and Pochan 2007; Fritzsche et al 2008; Kosmidou et al 2008; Passaglia et al 2008; Sengwa et al 2008, 2009a-c, 2010a, b; Wang et al 2008; Pandis et al 2009; Sengwa and Choudhary 2010, 2011). In addition, the characterization of dielectric properties of PCNs has attracted a lot of attention from on-line process monitoring and off-line measurements (Bur et al 2005; Noda et al 2005). Further, the synthesization of PCNs of low dielectric constant and loss has large applications in integrated circuits, microelectronic and insulating devices, and membrane technology (Treichel et al 1998; Tanaka et al 2004). The flexible and linear chain structure of PEO makes large ionic conduction of alkali salt mixed PEOMMT nanocomposites with improved mechanical and thermal properties for their use as a novel solid electrolyte material for rechargeable batteries at ambient temperature, which is also established by the dielectric/impedance spectroscopic measurements (Chen and Chang 2001; Chen et al 2001, 2002; Sandí et al 2003; Loyens et al 2005; Thakur et al 2006; Kim et al 2008; Pradhan et al 2008; Mohapatra et al 2009; Sengwa et al 2010c; Choudhary and Sengwa 2011a-c).

In the present paper, an attempt is made to characterize the dielectric behaviour and alternating current (a.c.) electrical conductivity of melt compounded hot-pressed nanocomposites consisting of PEO filled with organophilic montmorillonite (OMMT) clay. In order to confirm the effect of electrode polarization phenomena and bulk material properties, the impedance spectroscopy and electric modulus spectra were also investigated. The dielectric properties were used to confirm the extent of OMMT intercalation and exfoliation in PEO matrix and their effect on polymer chain dynamics. Further the synthesization of PEO-OMMT by melt compounding process is a rapid, least expensive and dry procedure, and the dielectric characterization can provide an idea for their direct use in the fabrication of microelectronic devices and membranes.

\section{Materials and methods}

\subsection{Materials}

PEO powder of molecular weight $600,000 \mathrm{~g} / \mathrm{mol}$ and organophilic montmorillonite (OMMT) clay surface modified

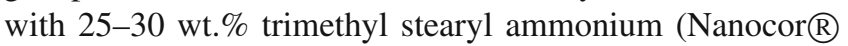
1.28 E) were purchased from Sigma-Aldrich, USA.

\subsection{Preparation of nanocomposite films}

For the preparation of PEO-OMMT films, firstly, the required amounts of PEO $(3 \cdot 00,2 \cdot 97,2 \cdot 94,2 \cdot 91,2 \cdot 85,2 \cdot 70$ and $2.40 \mathrm{~g})$ and OMMT $(0.00,0.03,0.06,0.09,0.15,0.30$ and $0.60 \mathrm{~g}$ ) of $3 \mathrm{~g}$ total weight for the OMMT weight fractions $(\mathrm{wt} \%)(0,1,2,3,5,10$ and 20 , respectively) were mechanically mixed using an agate mortar and pestle. After that each PEO-OMMT composition was melt compounded at $70{ }^{\circ} \mathrm{C}$, slightly higher than that of the melting temperature of PEO, $65{ }^{\circ} \mathrm{C}$ under 3 tons of pressure in $60 \mathrm{~mm}$ diameter stainless steel die with $1 \mathrm{~mm}$ spacer using hotpress polymer film making unit and thus melt intercalated PEO- $x$ wt $\%$ OMMT nanocomposite films of $1 \mathrm{~mm}$ thickness were obtained.

\subsection{Measurements}

Agilent 4284A precision LCR meter and Agilent 16451B solid dielectric test fixture were used for the dielectric measurements in the frequency range from $20 \mathrm{~Hz}$ to $1 \mathrm{MHz}$. Frequency dependent values of parallel capacitance, $C_{P}$, parallel resistance, $R_{p}$ and loss tangent, $\tan \delta$ (dissipation factor, $D)$, of the dielectric test fixture filled with nanocomposite film were measured for the determination of dielectric/ electrical spectra of the PEO- $x$ wt $\%$ OMMT films at $30^{\circ} \mathrm{C}$. Prior to sample measurements, the open circuit calibration was performed to eliminate the effect of stray capacitance of the dielectric test fixture (Agilent Technologies Ltd, Japan 2000). The evaluation of intensive quantities, viz. complex dielectric function, $\varepsilon^{*}(\omega)=\varepsilon^{\prime}-j \varepsilon^{\prime \prime}$, alternating current (a.c.), electrical conductivity, $\sigma^{*}(\omega)=\sigma^{\prime}+j \sigma^{\prime \prime}$ and, electric modulus, $M^{*}(\omega)=M^{\prime}+j M^{\prime \prime}$ and the extensive quantity i.e. complex impedance, $Z^{*}(\omega)=Z^{\prime}-j Z^{\prime \prime}$ of the PCNs films are described in detail elsewhere (Sengwa et al 2010c; Sengwa and Choudhary 2011).

\section{Results and discussion}

\subsection{Complex dielectric function and electric modulus spectra}

Figure 1 shows that the real part of complex dielectric function $\varepsilon^{\prime}$ of pure PEO and PEO-OMMT melt compounded films initially decrease with increase of frequency and approaches a constant value at $1 \mathrm{MHz}$, which corresponds to their static permittivity, $\varepsilon_{\mathrm{s}}$. Inset of figure 1 shows that the $\varepsilon_{\mathrm{s}}$ values of these nanocomposites vary anomalously with increase of OMMT concentration. The change in $\varepsilon^{\prime}$ or $\varepsilon_{\mathrm{s}}$ values of the PCNs has strong correlation with the predominance of intercalated and exfoliated structural properties of the dispersed clay in the polymer matrix (Kanapitsas et al 2002; Wang et al 2004a, b; Böhning et al 2005; Bur et al 2005; Noda et al 2005; Elmahdy et al 2006; Mijović et al 2006; Pluta et al 2007; Psarras et al 2007; Rao and Pochan 2007; Fritzsche et al 2008; Kosmidou et al 2008; Passaglia et al 2008; Sengwa et al 2008, 2009a-c, 2010a, b; Wang et al 2008; Pandis et al 2009; Sengwa and Choudhary 2010, 2011). It is well established that predominance of MMT exfoliation in the polymer matrix decreases the $\varepsilon^{\prime}$ value whereas intercalation increases it (Wang et al 2004a, b; Bur et al 2005; Noda et al 2005; Sengwa and Choudhary 2010, 2011; Sengwa et al 2010b, c). Due to hydrophilic behaviour, 


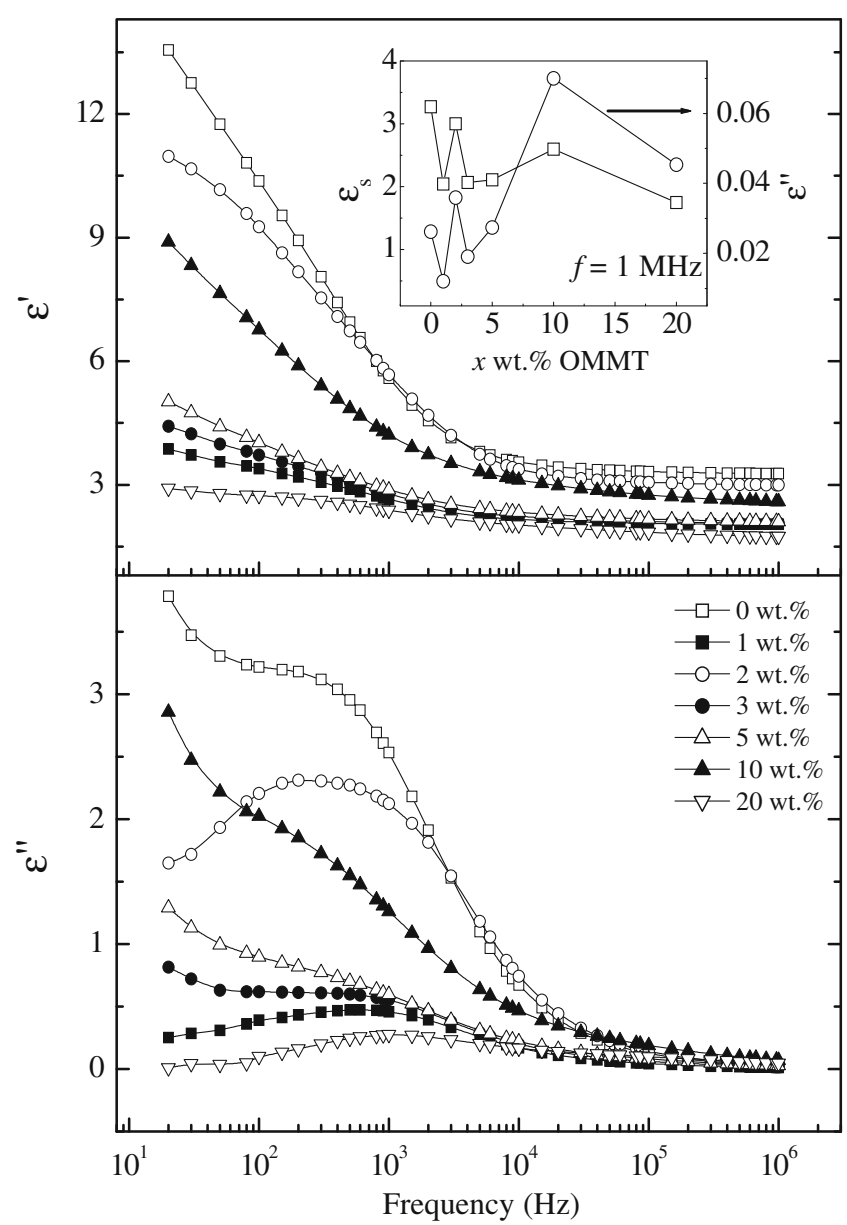

Figure 1. Frequency dependent real part, $\varepsilon^{\prime}$ and loss, $\varepsilon^{\prime \prime}$, of dielectric function of melt compounded PEO- $x$ wt $\%$ OMMT nanocomposite films at $30{ }^{\circ} \mathrm{C}$. Inset shows variation of static permittivity, $\varepsilon_{\mathrm{s}}^{\prime}$ ( $\varepsilon^{\prime}$ values) and loss $\varepsilon^{\prime \prime}$ at $1 \mathrm{MHz}$ against $x \mathrm{wt} \%$ OMMT.

PEO promotes the intercalation of its molecules in $\mathrm{Na}^{+}-$ MMT galleries and also have large adsorption on exfoliated nano-platelets surfaces (Shen et al 2002, 2003). After several attempts, the conformation of the intercalated PEO in MMT galleries is still controversial, which is mainly owing to the variation in the mixing process of clay in the PEO matrix, the type of clay used and the route of nanocomposite preparation (Homminga et al 2005; Hikosaka et al 2006). Further, on comparison with $\mathrm{Na}^{+}-\mathrm{MMT}$, the $\mathrm{NH}_{4}^{+}$-MMT surfaces have strong interaction with the adsorbed PEO chains, which also influences MMT structures in PEO matrix (Aranda and Ruiz-Hitzky 1999; Liu 2007).

In the present study, a large decrease in $\varepsilon_{\mathrm{s}}$ value with a loading of $1 \mathrm{wt} \%$ OMMT (inset of figure 1) confirms that OMMT exfoliation dominates over its intercalated structures. It seems that at $1 \mathrm{wt} \%$ OMMT, PEO chains cover more and more OMMT surfaces by adsorption and form the PEO-OMMT micro-aggregates. At $2 \mathrm{wt} \%$ OMMT, the $\varepsilon_{\mathrm{s}}$ value is close to that of virgin PEO film, which confirms the existence of an equal amount of intercalated and exfoliated
OMMT structures. The $\varepsilon_{\mathrm{s}}$ values at 3,5 and $20 \mathrm{wt} \%$ OMMT are found nearly equal to that of $1 \mathrm{wt} \%$ in PEO matrix, which inferred that OMMT exfoliated structures dominates at these concentrations, but their amount varies anomalously at these OMMT concentrations. Further, the low $\varepsilon_{\mathrm{s}}$ value of the nanocomposites as compared to pure PEO film reveals the decrease of crystalline amount of PEO when OMMT is used as filler. Further, at $1 \mathrm{MHz}$, the $\varepsilon_{\mathrm{s}}$ values of PEOOMMT films are in the range of 2-3 and the dielectric loss $\varepsilon^{\prime \prime}$ values are $<0.07$ (inset of figure 1 ), which suggests their applications as low dielectric constant materials at radio frequencies. These $\varepsilon_{\mathrm{s}}$ values of PEO-OMMT films are found to be in agreement with the aqueous solution cast PEO-MMT nanocomposite films (Sengwa and Choudhary 2011).

The $\varepsilon^{\prime \prime}$ spectra of PEO-OMMT films show the loss peak around $1 \mathrm{kHz}$, which is corresponding to dielectric relaxation of PEO segmental dynamics (local chain motion), and $\varepsilon^{\prime \prime}$ values are very small at high frequencies (figure 1). The $\varepsilon^{\prime \prime}$ peak are not sharp for some of the nanocomposite films, which may be either due to the contribution of ohmic conductivity or the Maxwell-Wagner interfacial polarization that occurs at the interfacing boundaries of different conductivity components in the composite material (Kremer and Schönhals 2003; Sengwa and Choudhary 2011). Due to independence of $\varepsilon^{\prime}$ from ohmic conductivity, the derivative of $\varepsilon^{\prime}$ denoted as $\varepsilon_{\text {deriv }}^{\prime \prime}$ (Fritzsche et al 2008) is used in order to confirm the contribution of conductivity effect in loss spectra, which is derived from the relation:

$$
\varepsilon_{\text {deriv }}^{\prime \prime}=-\frac{\pi}{2} \frac{\partial \varepsilon^{\prime}(\omega)}{\partial \ln (\omega)} \approx \varepsilon^{\prime \prime} .
$$

Figure 2 shows comparative spectra of $\varepsilon^{\prime \prime}$ and $\varepsilon_{\text {deriv }}^{\prime \prime}$ of PEO$1 \mathrm{wt} \%$ OMMT film. The inset of figure 2 also includes these spectra for pure PEO film. It is found that (1) is almost exact for these materials and the $\varepsilon_{\text {deriv }}^{\prime \prime}$ reproduces the measured frequency dependent $\varepsilon^{\prime \prime}$ data with sharp relaxation peak. Similar behaviour is also observed for various OMMT concentrations of these nanocomposite films. The values of PEO segmental relaxation time, $\tau_{\varepsilon}$, in these nanocomposites were evaluated from the loss peak frequency, $f_{\mathrm{p}}\left(\varepsilon^{\prime \prime}\right)$ in the $\varepsilon_{\text {deriv }}^{\prime \prime}$ spectra, using the relation (Sengwa et al 2010b; Sengwa and Choudhary 2010, 2011):

$$
\tau_{\varepsilon}=\left(2 \pi f_{\mathrm{p}}\left(\varepsilon^{\prime \prime}\right)\right)^{-1} .
$$

The significant upturn in $\varepsilon^{\prime}$ spectra at lower end side of the PEO-OMMT nanocomposites (figure 1) may be due to the contribution of electrode polarization (EP) effect or the Maxwell Wagner (MW) interfacial polarization process (Sengwa et al 2010b; Sengwa and Choudhary 2010, 2011). To confirm this EP effect, electric modulus spectra of the PEO-OMMT nanocomposites (figure 3) were analysed, which is a common practice used in solid dielectric materials (Thakur et al 2006; Kosmidou et al 2008; Pradhan et al 2008; Sengwa et al 2008, 2009c, 2010b; Sengwa and Choudhary 2010, 2011). The non-zero values of $M^{\prime}$ at lower 


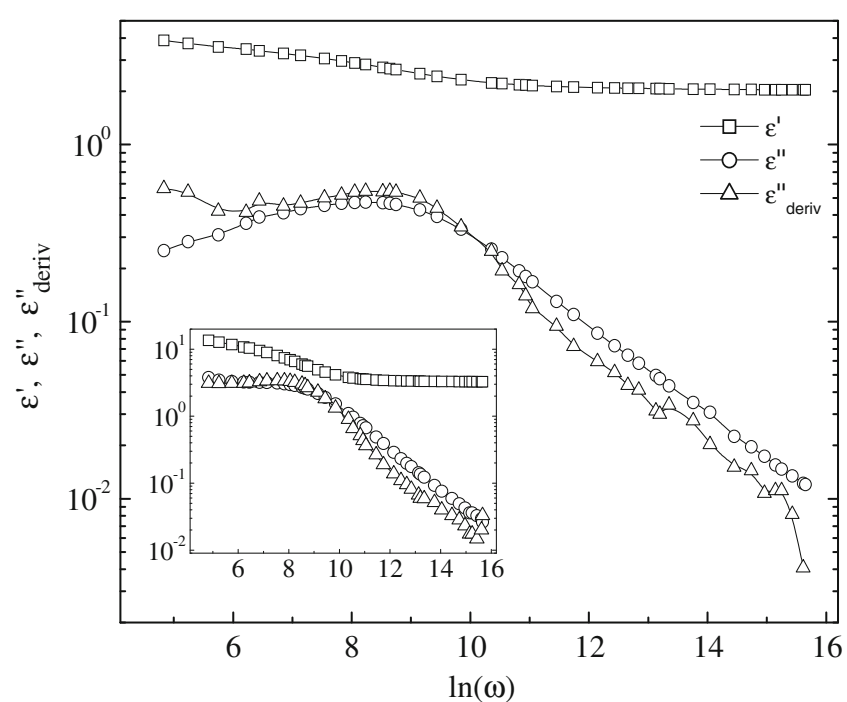

Figure 2. Comparative spectra of real part, $\varepsilon^{\prime}$, loss $\varepsilon^{\prime \prime}$ and $\varepsilon_{\text {deriv }}^{\prime \prime}$ of dielectric function of melt compounded PEO-1 wt\% OMMT nanocomposite film at $30^{\circ} \mathrm{C}$. Inset shows spectra for pure PEO film.

frequency end of the spectra suggest that the electrode polarization relaxation frequency for these materials is beyond the lower limit of experimental frequency range. Sharp peaks in $M^{\prime \prime}$ spectra can be attributed to the electric modulus or ionic conduction relaxation (Pradhan et al 2008; Choudhary and Sengwa 2011a-c), which are governed by the PEO segmental dynamics. The electric modulus relaxation time, $\tau_{\mathrm{M}}$, is determined from the frequency $f_{\mathrm{p}}\left(M^{\prime \prime}\right)$ corresponding to the modulus spectra peak using the relation (Sengwa and Choudhary 2010, 2011):

$$
\tau_{\mathrm{M}}=\left(2 \pi f_{\mathrm{p}}\left(M^{\prime \prime}\right)\right)^{-1} .
$$

\subsection{A.C. conductivity}

Figure 4 shows that the real part, $\sigma^{\prime}$, of a.c. conductivity of pure PEO and PEO-OMMT films increases by 3 orders of magnitude with an increase of alternating field frequency from $20 \mathrm{~Hz}$ to $1 \mathrm{MHz}$. Due to semicrystalline structures of PEO, the $\sigma^{\prime}(f)$ plots have straight lines of two different slopes, which are distinguished around the $\tan \delta$ peak frequencies. From figure 4, it can be seen that the lower frequency, $\sigma^{\prime}(f)$, straight line have higher value of slope as compared to their higher frequency. The $\sigma^{\prime}(f)$ values of PEO are found to be in good agreement with the earlier reported data at same temperature (Mishra and Rao 1998; Choudhary and Sengwa 2011a-c). The d.c. conductivity, $\sigma_{\mathrm{dc}}$, of these materials were estimated from the straight line fit of low frequency $\sigma^{\prime}$ spectra, and the same are plotted against OMMT concentration in the inset of figure 4. It is observed that up to $10 \mathrm{wt} \%$ OMMT loading in PEO matrix, the $\sigma_{\mathrm{dc}}$ values of these nanocomposites vary anomalously within one order of magnitude, but at $20 \mathrm{wt} \%$ OMMT there is a decrease in the

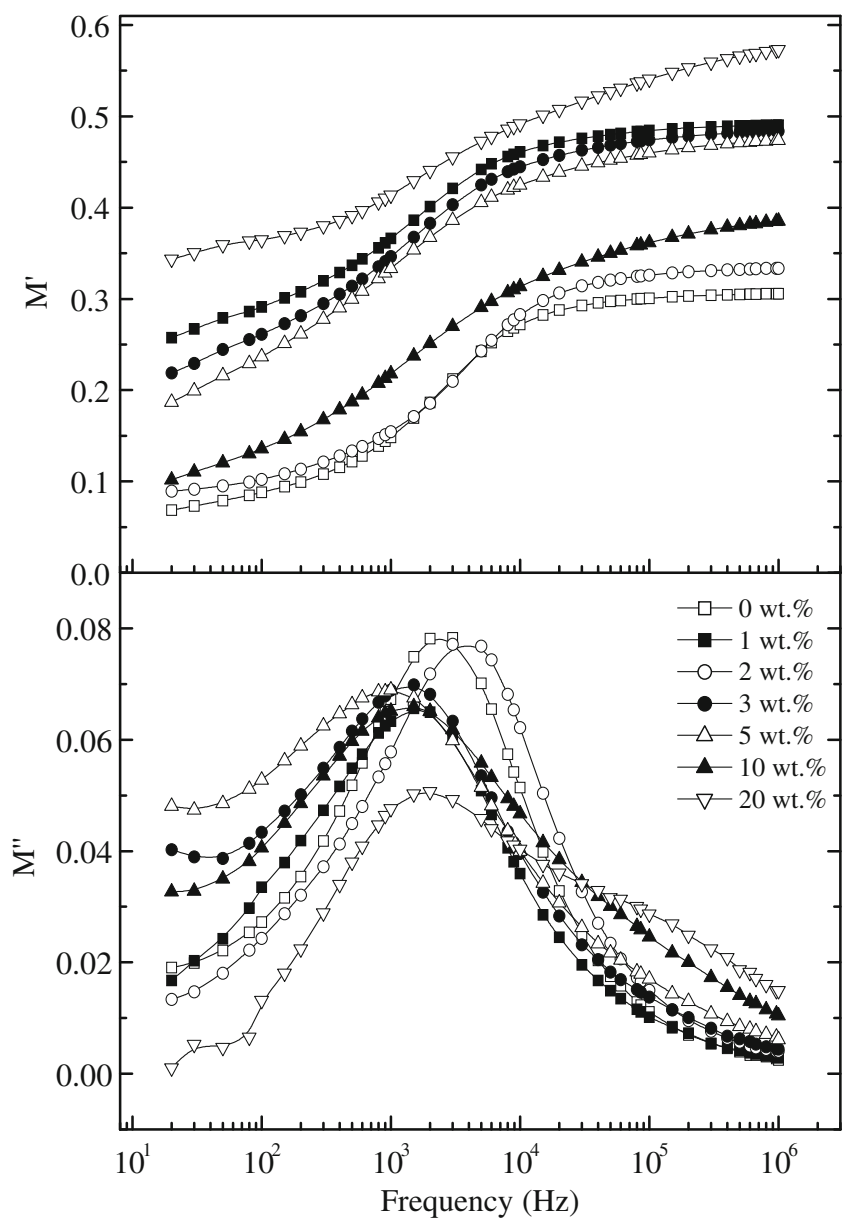

Figure 3. Frequency dependent real part, $M^{\prime}$ and loss, $M^{\prime \prime}$, of electric modulus of melt compounded PEO- $x \mathrm{wt} \%$ OMMT nanocomposite films at $30{ }^{\circ} \mathrm{C}$.

value of about three orders of magnitude. Further these $\sigma_{\mathrm{dc}}$ values of PEO-OMMT are found about one order of magnitude lower than that of aqueous solution cast PEO-MMT films (Sengwa and Choudhary 2011), which reveals that the mobility of bulky cation of OMMT is less as compared to that of the small cation $\left(\mathrm{Na}^{+}\right)$of MMT.

\subsection{Dielectric relaxation behaviour}

In figure 5 , we have plotted the comparative spectra of $\varepsilon^{\prime \prime}$, $M^{\prime \prime}, \tan \delta$ and $\sigma^{\prime}$ values of PEO-1 wt.\% OMMT nanocomposite as a representative plot. It is found that the $\tan \delta$ peak frequency for the nanocomposites lies between $\varepsilon^{\prime \prime}$ and $M^{\prime \prime}$ peak frequencies, which is the general characteristic of PCN materials (Sengwa et al 2010b; Sengwa and Choudhary 2010, 2011). From figure 5, it is also observed that the transitions in the slopes of $\sigma^{\prime}$ spectra occurs at frequency, $f_{\mathrm{p}}\left(M^{\prime \prime}\right)$.

Inset of figure 5 shows that $\tau_{\varepsilon}$ and $\tau_{\mathrm{M}}$ values of the PEOOMMT nanocomposites vary anomalously with increase in OMMT concentration. These values confirm that the PEO chain segmental motion and the ion conduction mechanism 


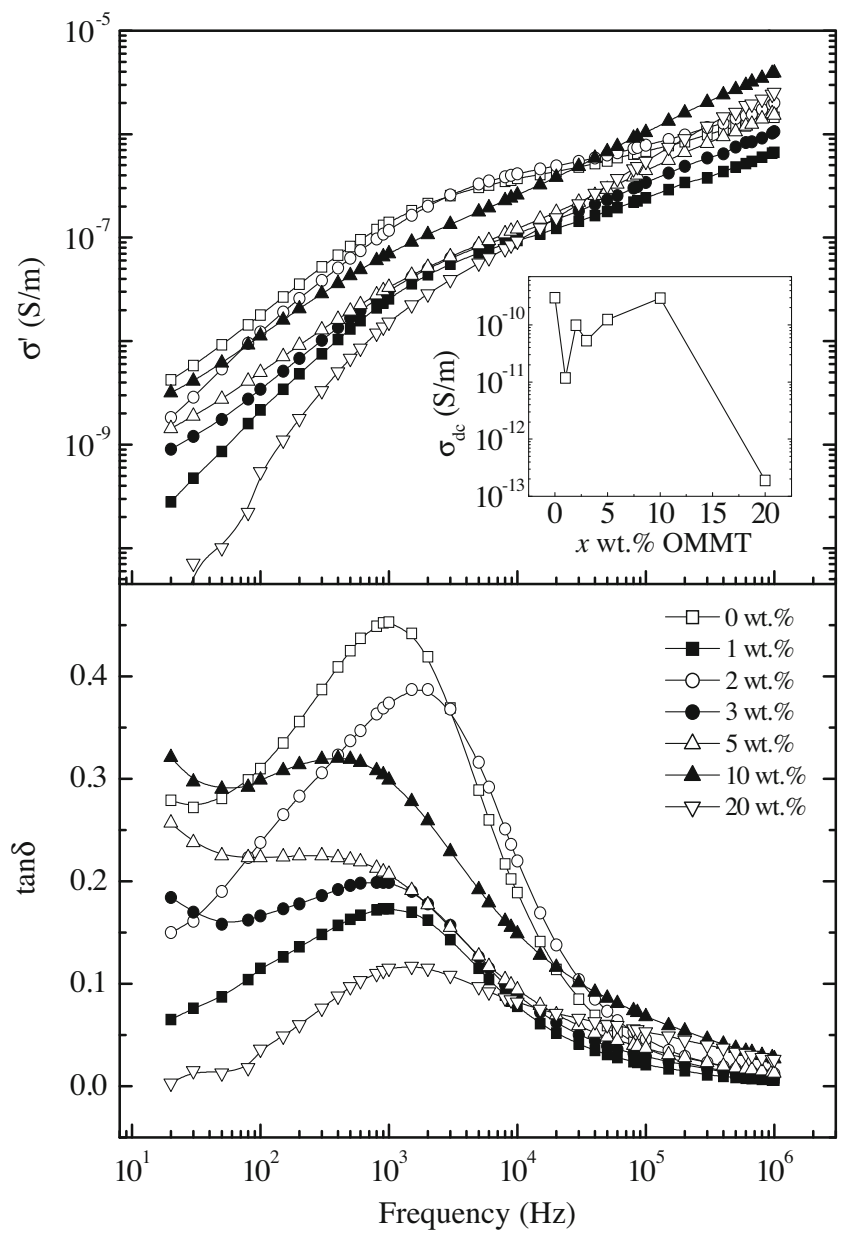

Figure 4. Frequency dependent real part of a.c. conductivity, $\sigma^{\prime}$ and loss tangent, $\tan \delta$, of the melt compounded PEO- $x$ wt. $\%$ OMMT nanocomposite films at $30{ }^{\circ} \mathrm{C}$. Inset shows variation of $\sigma_{\mathrm{dc}}$ with $x$ wt $\%$ OMMT.

are affected by the exfoliated and intercalated OMMT structures. The maximum in relaxation times at $5 \mathrm{wt} \%$ OMMT confirm the large hindrance to the PEO segmental dynamics and also the ionic motion. The $\tau_{\mathrm{M}}<\tau_{\varepsilon}$ revealed that the ionic motion is faster than that of the PEO chain segmental motion in the correlated structure of the nanocomposites. Further, the relaxation times of melt compounded PEO-OMMT films were found comparatively higher than that of the solution cast PEO-MMT films (Sengwa and Choudhary 2011), which revealed that the presence of organo ammonium salt on the OMMT nano-platelets surfaces form stronger interactions with ether oxygen of the PEO chain. The enhanced interactions produce large hindrance to the PEO chain segmental dynamics, which results in a comparatively higher relaxation times of PEO-OMMT films.

\subsection{Impedance spectra}

Figure 6 shows that the complex impedance plane plots $\left(Z^{\prime \prime}\right.$ vs $Z^{\prime}$ ) of the pure PEO and PEO-OMMT nanocompo-

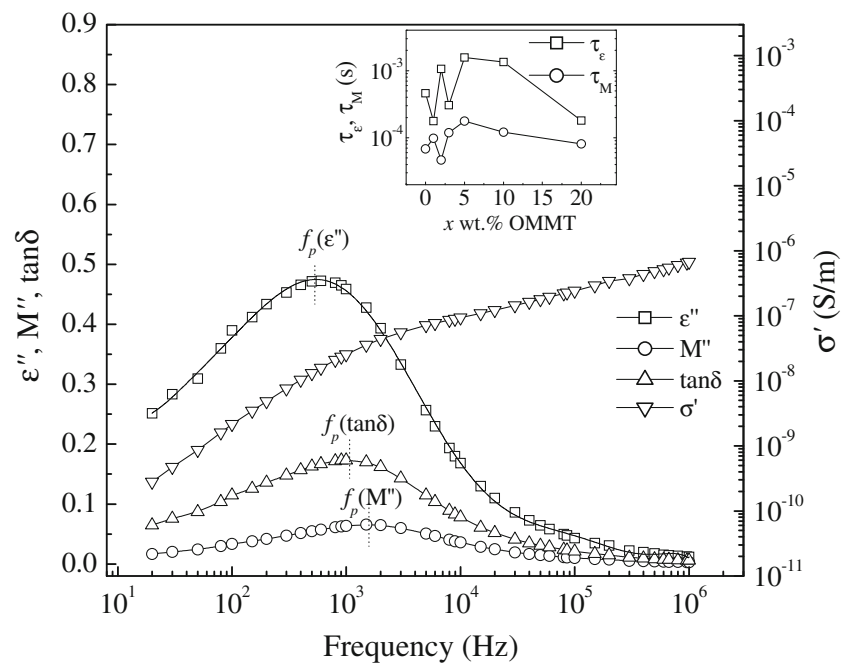

Figure 5. Comparison of $\varepsilon^{\prime \prime}, M^{\prime \prime}, \tan \delta$ and $\sigma^{\prime}$ spectra of melt compounded PEO-1 wt.\% OMMT nanocomposite film at $30{ }^{\circ} \mathrm{C}$. Inset shows variation of $\tau_{\varepsilon}$ and $\tau_{\mathrm{M}}$ with $x$ wt $\%$ OMMT.

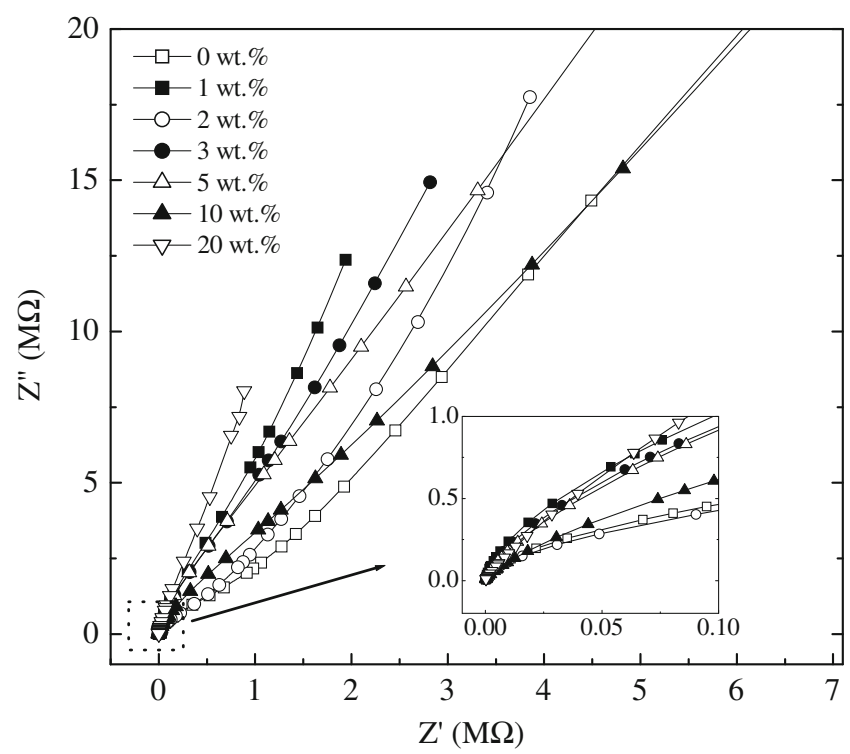

Figure 6. Complex impedance plane plots $\left(Z^{\prime \prime}\right.$ vs $\left.Z^{\prime}\right)$ of melt compounded PEO- $x$ wt $\%$ OMMT nanocomposite films at $30{ }^{\circ} \mathrm{C}$. Inset shows enlarged view at high frequencies.

sites start from the origin and incline at different angles to the real axis. The shape of impedance spectra of a material gives information regarding the electrode polarization (formation of electric double layer between the electrodes and the dielectric material interfaces) and about the current carriers whether they are electrons or ions (Thakur et al 2006; Pradhan et al 2008; Sengwa et al 2008, 2009b, c; Choudhary and Sengwa 2011a-c). Generally ion conducting materials show two different arcs corresponding to electrode polarization in lower frequency region and bulk material properties in upper frequency region (Sengwa et al 2010c; Choudhary and Sengwa 2011a-c). For the PEO-OMMT 
nanocomposites, single arcs represent the bulk material property, which implies that the charge transfer between the material and the electrodes is not influenced by the electric double layer (EP effect). The appearance of single arcs in complex impedance plane plots also suggests a good electrical contact between the PEO-OMMT films and the nickel-plated cobalt electrodes. These plots suggest that the significant increase in $\varepsilon^{\prime}$ at low frequencies may be mainly due to MaxwellWagner interfacial polarization. The large values of $Z^{\prime \prime}$ as compared to the $Z^{\prime}$ confirm a high capacitive behaviour of these nanocomposite films, which is owing to their low value of d.c. conductivity.

\section{Conclusions}

Here we present detailed structural analysis of PEO-OMMT nanocomposites using various formalisms of dielectric processes. The significant decrease of $\varepsilon_{\mathrm{s}}$ at $1 \mathrm{wt} \%$ OMMT loading is the evidence of predominance of exfoliated OMMT structures in PEO matrix, whereas at $2 \mathrm{wt} \%$ OMMT the $\varepsilon_{\mathrm{s}}$ value equal to that of pure PEO film confirms the nearly equal amount of OMMT exfoliated and intercalated structures. The dielectric study revealed that the $\varepsilon_{\mathrm{S}}$ value at radio frequencies can be tuned by loading 1 to 2 wt $\%$ OMMT in the PEO matrix and synthesization by melt compounding technique for their use as low dielectric constant nanocomposite materials in microelectronic technology. The d.c. conductivity of these PEO based films vary within one order of magnitude with OMMT loading up to $10 \mathrm{wt} \%$. The dielectric and electric modulus relaxation times confirm that in the correlated structures of nanocomposites, the a.c. ionic conduction relaxation is faster than that of the PEO chain segmental dynamics. The hindrance to the PEO segmental motion due to ion-dipolar interactions with OMMT is stronger than that of the PEO interaction with $\mathrm{Na}^{+}-\mathrm{MMT}$.

\section{Acknowledgements}

Authors are grateful to the Department of Science and Technology, New Delhi, for providing experimental facilities through project No. SR/S2/CMP-09/2002. One of the authors (SC) is thankful to the University Grants Commission, New Delhi, for the award of a Research Fellowship in Science for Meritorious Students (RFSMS).

\section{References}

Agilent 2000 Solid test fixture-Operation and service manual (Japan: Agilent Technologies Ltd) 16451B

Aranda P and Ruiz-Hitzky E 1999 Appl. Clay Sci. 15119

Böhning M, Goering H, Fritz A, Brzezinka K W, Turky G, Schönhals A and Schartel B 2005 Macromolecules 382764

Bur A J, Lee Y H, Roth S C and Start P R 2005 Polymer 4610908 Chaiko D J 2003 Chem. Mater. 151105

Chen B and Evans J R G 2004 J. Phys. Chem. B108 14986

Chen H W and Chang F C 2001 Polymer 429763
Chen H W, Chiu C Y, Wu H D, Shen I W and Chang F C 2002 Polymer 435011

Chen W, Xu Q and Yuan R Z 2001 Compos. Sci. Technol. 61935

Choudhary S and Sengwa R J 2011a Ionics (DOI: 10.1007/s11581011-0585-8)

Choudhary S and Sengwa R J 2011b Indian J. Pure Appl. Phys. 49 204

Choudhary S and Sengwa R J 2011c Indian J. Eng. Mater. Sci. 18 147

de Bruyn J R, Pignon F, Tsabet E and Magnin A 2008 Rheological Acta 4763

Elmahdy M M, Chrissopoulou K, Afratis A, Floudas G and Anastasiadis S H 2006 Macromolecules 395170

Fritzsche J, Das A, Jurk R, Stöckelhuber K W, Heinrich G and Klüppel M 2008 Express Polym. Lett. 2373

Hikosaka M Y, Pulcinelli S H, Santilli C V, Dahmouche K and Craievich A F 2006 J. Non-Cryst. Solids 3523705

Homminga D, Goderis B, Dolbnya I, Reynaers H and Groeninckx G 2005 Polymer 4611359

Kanapitsas A, Pissis P and Kotsilkova R 2002 J. Non-Cryst. Solids 305204

Kim S, Hwang E J, Jung Y, Han M and Park S J 2008 Colloid Surface A313-314 216

Kosmidou T V, Vatalis A S, Delides C G, Logakis E, Pissis P and Papanicolaou G C 2008 Express Polym. Lett. 2364

Kremer F and Schönhals A 2003 Broadband dielectric spectroscopy (New York: Springer-Verlag)

Liao B, Song M, Liang H and Pang Y 2001 Polymer 4210007

Lin-Gibson S, Kim H, Schmidt G, Han C C and Hobbie E K 2004 J. Colloid Interf. Sci. 274515

Liu P 2007 Appl. Clay Sci. 3864

Liu T, Chen B and Evans J R G 2008 Bioinsp. Biomim. 3016005

Loyens W, Maurer F H J and Jannasch P 2005 Polymer 467334

Mijović J, Lee H, Kenny J and Mays J 2006 Macromolecules 39 2172

Mishra R and Rao K J 1998 Solid State Ionics 106113

Miwa Y, Drews A R and Schlick S 2008 Macromolecules 41 4701

Mohapatra S R, Thakur A K and Choudhary R N P 2009 J. Power Sources 191601

Nelson A and Cosgrove T 2004 Langmuir 20 2298, 10382

Noda N, Lee Y H, Bur A J, Prabhu V M, Snyder C R, Roth S C and McBrearty M 2005 Polymer 467201

Ogata N, Kawakage S and Ogihara T 1997 Polymer 385115

Pandis C et al 2009 J. Polym. Sci.: Part B: Polym. Phys. 47407

Passaglia E, Bertoldo M, Ciardelli F, Prevosto D and Lucchesi M 2008 Eur. Polym. J. 441296

Pluta M, Jeszka J K and Boiteux G 2007 Eur. Polym. J. 432819

Pradhan D K, Choudhary R N P and Samantaray B K 2008 Express Polym. Lett. 2630

Psarras G C, Gatos K G, Karahaliou P K, Georga S N, Krontiras C A and Karger-Kocsis J 2007 Express Polym. Lett. 1837

Rao Y and Pochan J M 2007 Macromolecules 40290

Reinholdt M X, Kirkpatrick R J and Pinnavaia T J 2005 J. Phys. Chem. B109 16296

Sandí G, Carrado K A, Joachin H, Lu W and Prakash J 2003 J. Power Sources 119-121 492

Sengwa R J and Choudhary S 2010 Express Polym. Lett. 4559

Sengwa R J and Choudhary S 2011 J. Macromol. Sci. Part B: Phys. $\mathbf{5 0} 1313$

Sengwa R J, Choudhary S and Sankhla S 2008 Express Polym. Lett. 2800 
Sengwa R J, Choudhary S and Sankhla S 2009a Colloid Surface A336 79

Sengwa R J, Choudhary S and Sankhla S 2009b Polym. Int. 58781

Sengwa R J, Sankhla S and Choudhary S 2009c Colloid Polym. Sci. 2871013

Sengwa R J, Choudhary S and Sankhla S 2009d Indian J. Eng. Mater. Sci. 16395

Sengwa R J, Sankhla S and Choudhary S 2010a Indian J. Pure Appl. Phys. 48196

Sengwa R J, Choudhary S and Sankhla S 2010b Compos. Sci. Technol. 701621

Sengwa R J, Sankhla S and Choudhary S 2010c Ionics 16697

Shen Z, Simon G P and Cheng Y B 2002 Polymer 434251

Shen Z, Simon G P and Cheng Y B 2003 Eur. Polym. J. 391917
Strawhecker K E and Manias E 2003 Chem. Mater. 15844

Tanaka T, Montanari G C and Mülhaupt R 2004 IEEE Trans. Dielect. Elect. Insul. 11763

Thakur A K, Pradhan D K, Samantaray B K and Choudhary R N P 2006 J. Power Sources 159272

Treichel H, Ruhl G, Ansmann P, Würl R, Müller Ch and Dietimeier M 1998 Microelect. Eng. 401

Tunney J J and Detellier C 1996 Chem. Mater. 8927

Wang H W, Chang K C, Yeh J M and Liou S J 2004a J. Appl. Polym. Sci. 911368

Wang H W, Chang K C, Chu H C, Liou S J and Yeh J M 2004b J. Appl. Polym. Sci. 922402

Wang J H, Liang G Z, Yan H X and He S B 2008 Express Polym. Lett. 2118 